\title{
A critical review on the translational journey of cardioprotective therapies!
}

Xavier Rossello, $\mathrm{MD}^{1}$, Derek M. Yellon, PhD, DSc, FRCP ${ }^{1,2}$

${ }^{1}$ The Hatter Cardiovascular Institute, University College London, London, United Kingdom

${ }^{2}$ NIHR UCLH Biomedical Research Centre, University College London Hospital \& Medical School, London, United Kingdom

Both authors take responsibility for all aspects of the reliability and freedom from bias of the data presented and their discussed interpretation.

\section{Corresponding Author:}

Derek M. Yellon, The Hatter Cardiovascular Institute, University College London,

67 Chenies Mews, London WC1E 6HX 2, United Kingdom. Email: d.yellon@ucl.ac.uk

\section{Acknowledgments of grant support}

This work was supported by a proportion of funding from the Department of Health's NIHR Biomedical Research Centres funding scheme of which DM Yellon is a Senior Investigator. Dr Rossello has received support from the Fundacion Alfonso Martin Escudero fellowship grant.

\section{Conflicts of interest}

The authors report no relationships that could be construed as a conflict of interest.

\section{Keywords}

Ischemia reperfusion injury; outcomes research, ST-segment elevation myocardial infarction

"Success consists of going from failure to failure without the loss of enthusiasm" Winston Churchill 


\begin{abstract}
The failure to translate novel cardioprotective therapies tested in pre-clinical studies into the clinical setting for patient benefit can be attributed to a number of factors at different stages of the research process. This review focuses on the evidences and the gaps with regard to the translational journey of cardioprotective interventions. Gaps are classified into 3 main groups: 1) those related to pre-clinical studies, 2) those associated with the validation of infarct size as a good surrogate and 3) those based on design and interpretation of randomized clinical trials on cardioprotection. Addressing these gaps might increase the chances to successfully translate cardioprotective therapies into improving both post-STEMI heart failure and cardiovascular death rates.
\end{abstract}




\section{Introduction}

Acute myocardial infarction presenting as ST-segment elevation (STEMI) is the result of abrupt occlusion of an epicardial coronary artery, usually due to a sudden rupture of an atherosclerotic plaque. Early reperfusion by primary percutaneous coronary intervention (PPCI) limits myocardial infarct size (IS) and changes the fate of the myocardium at risk[1]. However, the process of restoring blood flow to the ischemic myocardium induces additional myocardial damage, known as "myocardial ischemia-reperfusion injury (IRI)"[2], that negatively impacts on IS and on mortality rates.

In 1971, Braunwald et al proposed that the extent and severity of tissue damage after coronary occlusion could be modified by therapeutic manipulations applied during ischemia[3]. This work was the starting signal for several studies testing therapies designed to limit myocardial IS, also known as cardioprotective therapies. Although cardiovascular research in the 1970 s was dominated by interventions aimed at limiting IS by pharmacotherapy in the absence of reperfusion (prethrombolytic era), the concept of cardioprotection eventually evolved to include therapies designed to limit myocardial injury during ischemia and reperfusion [4].

Cardioprotective therapies might be applied in a wide spectrum of patients[2]. Nevertheless, this review focuses on those presenting with a STEMI treated by PPCI. Many interventions limiting myocardial IRI and reducing IS in experimental animal studies have been tested in this setting. Promising results in a number of "proof of concept" studies have been obtained with regard to their myocardial infarct-sparing effect, however a few disappointing results have also been raised in terms of clinical outcomes benefit (Table 1).

The failure to translate novel cardioprotective therapies discovered in pre-clinical studies into the clinical setting for patient benefit can be attributed to a number of factors at different stages of the research process. This review summarizes the evidences and the gaps with regard to the translational journey on cardioprotection. The aim is to note deficiencies and encourage improvements in the translation of cardioprotective therapies, classifying the gaps into 3 main groups: 1) those related to 
pre-clinical studies, 2) those associated with the validation of IS as a good surrogate, and 3) those based on design and interpretation of randomized clinical trials (RCTs) on cardioprotection, including all the uncontrolled factors in the clinical setting.

\section{The pre-clinical gap}

Most of our knowledge about acute myocardial infarction (AMI) is derived from pre-clinical studies, although experimental animal models are used as approximations of human pathophysiology and it is fair to acknowledge that they present many limitations.

\subsection{Myocardial IRI model}

Remarkable differences exist between animal models and patients with STEMI, as seen in Table 2. For instance, animals do not have atherosclerosis and the experimental infarct is caused by external compression or ligation of the artery, lacking the potential for embolization. Reperfusion in experimental models is usually successful and shorter than those registered in patients[5]. Moreover, the duration of reperfusion used in experimental models of acute IRI varies with the model, while in STEMI patients reperfusion is unlimited and IS assessment may occur several days after reperfusion. Time of IS evaluation is important not only because myocardial IS depends on both the duration of ischemia and the length of the reperfusion period[6], but also because the tissue response to IRI progresses dynamically over time, following a bimodal pattern as has been recently described[7].

\subsection{Animal models}

Differences in animal physiology should be considered when attempting to translate an intervention[8]. Jones et al[9] in the framework of the CAESAR (Consortium for preclinical assessment of cARdioprotctive therapies) initiative described a species-related effect-size gradient when ischemic preconditioning (IPC) was applied, stressing the fact that successful extrapolation of animal results into clinics might depend on the species being evaluated. As a general rule, rodent models are optimal when testing a novel therapy and trying to identify potential mechanisms, whilst 
large-animal models, with a much closer match to human physiology, are more useful as a first step prior to performing proof-of-concept studies in the clinical arena[5].

\subsection{Reductionist models}

The essence of performing experiments in animal models is to effectively control variables in order to examine the real effect of any intervention. However, in the clinical setting, new cardiovascular medications are commonly tested on a background of guidelines and recommended therapies that include the standard of care[10,11].

In laboratory bench models, a single intervention therapy is studied without the background of other therapies. This reductionist approach has provided novel mechanistic understanding, but does not adequately represent actual clinical situations. Hence, the effects of background medications are frequently overlooked and the expected effects of any particular cardioprotective therapy combined with the other are largely unknown. Interestingly, the co-application of two or more drugs might have a synergistic effects. Although the study of combining medications has not been properly addressed, some studies have reported benefits. For instance, Downey et al reported synergistic effects when applying three different interventions in rats[12], and a recent clinical study by Eitel et al reported enhanced cardioprotective effects when remote ischemic conditioning (RIC) and ischemic postconditioning (IPOST) were co-applied compared to separate administration of these interventions [13]. Further, the concomitant activation of two parallel and different signalling pathways conferring additional cardioprotection has been described by Bell et al[14].

A large body of literature suggests that co-morbidities such as diabetes, hypercholesterolemia, hypertension or aging can have substantial impact on the effectiveness of cardioprotective interventions. Despite their prevalence in the clinical setting, many pre-clinical studies do not adequately represent these and other co-morbid conditions.

Future animal studies on cardioprotection (especially prior to clinical trial) will have more chance to be translated if conducted on a background of standard medication and co-morbidities[15]. 
Nevertheless, reductionist models are still very important to develop an improved understanding of cardioprotective signalling and can act as a good initial screening model.

\subsection{Reproducibility and reporting}

Concerns have been raised lately on reproducibility and reporting the results in preclinical studies[16]. Not all research findings are reproducible and it is doubtful that the beneficial effects of any specific cardioprotective therapy would be replicated in the complex clinical setting if the results were not reproducible in the highly controlled experimental setting. The problem is magnified by the bias towards the publication of positive results and by the lack of formal request by journals of prespecified protocol design, as it happens with randomized clinical trials.

The lack of reproducibility of scientific papers is an unresolved problem that might have some causes[17], such as the differences in experimental setting and protocols between (and even within) laboratories and the occasional lack of a full and comprehensive methods section allowing results to be reproduced by others .

Several initiatives by investigators could help address the issue of reproducibility of data and improve the quality of reporting in scientific publications. If the experimental data is inconsistent and/or insufficient, performing meta-analyses might be a good method to measure whether a cardioprotective effect is robust enough to be tested in randomized clinical trials (RCT). Whilst IPC has been shown to have a consistent effect in a large meta-analysis[18], other therapies have shown less solid results in meta-analyses based on pre-clinical studies. For instance, in a meta-analysis of 20 in vivo experimental studies in IRI animal models[19], the overall IS-reducing effect of cyclosporine was shown to be remarkably variable with no overall effect observed in swine models. This metaanalysis would be of great value before conducting clinical outcomes studies that subsequently have shown neutral results. A recent meta-analysis [20] has shown a positive effect of adenosine treatment on heart failure outcome in STEMI patients when intracoronary adenosine is administered as an adjunct to reperfusion, generating a hypothesis which could be confirmed by an adequately designed large-scale clinical trial. Thus, in the clinical setting, we might take advantage of published studies to 
consolidate data into large meta-analyses in which variables not addressed by each single study can be observed, for e.g. patient selection, doses, time and route of administration of drugs/interventions. This would help successfully design subsequent clinical trials in which the efficacy of treatments on specific patient population can be evaluated conclusively.

Guidelines such as those proposed by the ARRIVE (Animal Research: Reporting of In Vivo Experiments) [21] and Open Science Framework should also might help to improve the quality and transparency of data reporting in publications.

\section{The surrogate validation gap}

In a sequential approach, once robust data confirming IS-limiting effect is obtained from animal experiments , performing a "proof-of-concept" clinical trial is the subsequent logical step[22]. If such RCT using a surrogate endpoint brings promising results, larger multicentre RCTs will be required to determine whether these therapeutic interventions can actually improve major clinical outcomes in STEMI patients treated by PPCI, leading finally to the incorporation of the novel therapy into clinical practice.

In this section the focus is on the use of IS as a surrogate endpoint. Many reasons explain why it has been widely used to test the efficacy of cardioprotective therapies. First, IS has been historically recognized as the experimental hallmark of cardioprotection and can be measured using triphenyltetrazolium chloride staining with relative ease, although blinded analysis is required to avoid subjectivity in selection of lesion area. Second, IS reduction is achievable in clinical practice, as has been shown initially by thrombolysis and subsequently by PPCI. Third, IS reduction is considered a major determinant of prognosis[4]. Finally, IS has well-defined statistical characteristics: as a binary event (dead or alive), myocardial infarction should be a robust and unambiguous endpoint[4], although its measurement threshold present some difficulties and controversies (ie standard deviation used to define remote or at risk myocardium using magnetic resonance imaging). However, in spite 
of its widespread use, no true surrogacy has been established between IS and clinical outcomes, considering the strict criteria that are currently used_[23].

\subsection{The rationale behind the use of surrogate endpoints}

Therapies able to reduce IS are tested under the hypothesis that smaller infarctions will result in fewer adverse clinical events in the long-term. This paradigm is based on the assumption that the prognosis after an STEMI is greatly dependent on the amount of myocardium that undergoes irreversible injury [16].

\subsection{The lack of "strict" validation of infarct size as a surrogate endpoint}

The use of surrogate endpoints requires prior validation[23]: it should be consistently measurable and sensitive to the intervention, it should predict events and moreover, its response to an intervention should predict the response to the intervention in a RCT using clinical outcomes. As shown in figure 1, according to Domanski et al[24] five criteria are needed to validate a surrogate endpoint.

Despite IS not being a true surrogate (see figure 1), we believe it is still reasonable to use it as a marker of clinical outcome as it can be affected by specific cardioprotective strategies and is known to be associated with a biological effect. However, more attention should be paid to the increasing use of left ventricular systolic function as a surrogate endpoint for heart failure, since STEMI patients have an increasing rate of heart failure admissions as well as a decreasing mortality rate.

\subsection{Additional problems in using IS as a surrogate endpoint}

The extent of myocardial injury depends not only on duration of ischemia, but also on the location of the acute coronary occlusion as well as in the presence of collateral flow. Hence, IS in STEMI patients presents wide variations[5], although RCT on cardioprotection usually show smaller infarcts than those reported in clinical registries [5].

It is unknown whether the relationship between the duration of the ischemic insult and the extent of myocardial necrosis is linear or, on the contrary, it follows a monotonic non-linear relationship. This gap in our knowledge is important in order to elucidate whether myocardial IS reduction with a 
cardioprotective intervention is greater in patients presenting with early or late reperfusion. There is increasing evidence supporting the idea that the shorter the ischemic time, the greater the benefit in terms of myocardial salvage. Hence, those presenting with early reperfusion are most likely to benefit from the intervention[25]. For instance, in a RCT testing exenatide [26], myocardial salvage was achieved only in those patients presenting within 2-3 h of chest pain onset. On the contrary, it is also plausible that interventions in patients with timely reperfusion and subsequent small infarcts make no difference in terms of tissue salvage.

The nature of the relationship between ischemia duration and cardiovascular death is also uncertain. If the surrogacy is reliable, late reperfusion is expected to result in less myocardial salvage and consequently in a higher mortality rate, in comparison with early reperfusion. The relationship between time to reperfusion and mortality as a continuous function has previously been addressed but with conflicting results. De Luca et al showed a linear relationship in which the risk of 1-year mortality is increased by $7.5 \%$ for each 30-minute delay in PPCI[27]. However, such a positive linear relationship has been largely criticized and it is currently accepted that the first 2-to-3h represents the narrowness of the "golden window", followed by a continued mortality benefit of decreasing magnitude over time[28].

Finally, it is completely unknown how potent an IS-limiting effect needs to be to have a meaningful impact on clinical outcomes. Potentially, no impact might be noticed until a particular IS threshold is achieved. In this regard, one study has suggested that a reduction of IS to $<20 \%$ of the LV seems to be a reasonable target for an IS-limiting therapy to prevent mortality and heart failure after AMI[29]. Thus, this study suggested that in $25 \%$ of patients, only those with infarcts larger than $20 \%$, might likely present an event in the future, subsequently representing the true population that would benefit from the application of a cardioprotective drug during reperfusion therapy [29]. However it is important to point out that most of the studies which drew this conclusion were performed in the thrombolytic era. 


\section{The gap in clinical studies}

\subsection{Study design}

Like any experiment in the laboratory, a RCT is also defined by the controlled factors and the allocation of the intervention decided by the researcher. As it happens with experiments, when a RCT has a neutral effect (the null hypothesis is not rejected), several factors needs to be analysed to understand the discordance between the pre-clinical and the clinical studies.

\subsubsection{Selection of patients}

The eligibility criteria of a RCT determine the population of patients to which the trial findings can be extrapolated [30]. Overall, RCTs on cardioprotection have established several entry criteria in order to avoid treatment effect dilution. Thus, the location of the AMI has been widely used as a restrictive criterion, under the assumption that focusing on larger infarcts might provide further room to protect, as well as higher rates of cardiovascular events at follow-up. Whether these eligibility criteria helps to detect a real clinical benefit remains uncertain. Cardioprotective therapies have mostly shown successful results in reduction of infarct size studying anterior infarcts. For instance, metoprolol proved effective when applied in this setting [31], but failed to demonstrate cardioprotection in a non-restricted population[32]. In any case, restricting patient selection has to be balanced with the potential application of the result to a broad spectrum of STEMI patients.

\subsubsection{Baseline clinical characteristics of the patients}

A recurrent issue in our field is whether baseline clinical characteristics have a meaningful impact on the results. Major determinants of IS including duration of ischemia, area at risk and collateral blood flow; are expected to be well distributed in the selected patients and treatment arms due to the randomized allocation and appropriate sample size.

\subsubsection{Timing of treatment}

Any cardioprotective intervention can be given prior to or at the time of PPCI to reduce myocardial IS and preserve LV systolic function, thereby potentially improving survival and 
preventing heart failure in reperfused STEMI patients. Thus, treatment might be administered at any time between first patient contact and time of reperfusion, either using oral, intravenous or an intracoronary route.

Unlike administering the intervention at the time of PPCI (in the cath lab), it seems more beneficial to do so at an earlier time-point, in the ambulance whilst in transit to the PPCI centre, as has been demonstrated in several proof-of-concept clinical studies on RIC [33], glucose-insulin-potassium therapy[34] and metoprolol[31,35]. In fact, two recent sub-analyses on metoprolol and remote ischemic conditioning suggest a larger IS reduction when therapy is applied early [36,37].

\subsubsection{Primary endpoints}

Composite primary endpoints comprising several nonfatal events, such as MI and stroke along with cardiovascular mortality, are commonly used in RCT of STEMI [38]. Inclusion of some extra components such as unstable angina or ischemia-driven revascularization to the composite endpoint provide broader major adverse $\mathrm{CV}$ events composite. This would boost the numbers of events but may dilute the effect and meaning of the composite, since the most frequent event is often least clinically relevant. Moreover, not all these major adverse cardiac events equally reflect the myocardial IS-limiting effect of the intervention. Thus, events such as stroke and coronary revascularization are less likely to be influenced by a myocardial IS-limiting study intervention than rates of cardiac death and hospitalization for heart failure[39]. Also, the outcome optimization always needs to be placed in perspective alongside costs. The CIRCUS trial (Cyclosporine to ImpRove Clinical oUtcome in STelevation myocardial infarction patients), a multicenter double-blind RCT studying the clinical impact of cyclosporine, a mitochondrial permeability transition pore inhibitor, illustrates perfectly the problem of RCTs on cardioprotection when trying to balance the chosen outcomes and the costs involved[40]. Although this RCT was originally conceived for the composite of death or rehospitalization for heart failure as the primary outcome, two new outcomes (worsening of heart failure during the initial hospitalization and adverse left ventricular remodeling within 1 year) were added to the criteria due to limited funding and resultant necessity to reduce the sample size. 
To sum up, the effect of cardioprotective interventions may be diluted when including soft events (see above) into composite primary endpoints. This issue might be addressed with a win ratio approach, in which not all outcomes from the composite have the same weight[41]. It is also needed to balance the cost of an increasing sample size with outcome benefit.

\subsubsection{Sample size}

The progressive drop of event rates in the last decades due to the increasing use of evidence-based therapies[40] has made it unpredictable and harder to achieve the expected event rate in both the control and the intervention group of any RCT conducted in STEMI patients. Moreover, the absolute risk of a poor outcome in RCT control groups is usually lower than in real-world registries. In general, RCT patients have different baseline characteristics with regard to age, comorbidities, and drug treatments, and accordingly, have a lower mortality and lower event rate than non-participants[30]. For instance, in a recent registry of patients treated with PPCI for STEMI[42], the 1-year mortality rate was $11.4 \%$, whilst in the recently published CIRCUS trial it was about 7\%[40]. In the same way, some studies might be considered underpowered due to an unexpected small infarct size. Hence, the EARLY-BAMI trial which was powered to detect a reduction in IS from $28 \%$ to $23.5 \%$, showed that the final estimated IS was actually $15.1 \%$. This is a major concern, since RCT statistical power depends mainly on the total number of patients in the trial experiencing the primary event at followup.

In general, RCTs on cardioprotective therapies have presented small sample sizes, compared to other RCTs showing clinical benefits on STEMI patients. For instance, the GUSTO-1 (Global Utilization of Streptokinase and Tissue Plasminogen Activator for Occluded Coronary Arteries), which compared four thrombolytic strategies, included 41000 patients[43], whilst RCT on cardioprotection barely include more than 1000 patients.

In this context, it is important to state that, the smaller the RCT, the larger the magnitude of treatment difference needs to be to reach statistical significance. 


\subsection{The reality checkpoint}

The "real" gap is composed of all these factors that can mitigate the effect of any cardioprotective strategy being tested and, consequently, confound the interpretation of the results of RCTs. It might be also defined as the reality checkpoint, given that most of these factors are unavoidable barriers to deal with for any potential successfully translated cardioprotective intervention.

\subsubsection{Major confounding factors before reperfusion}

\subsubsection{Cardiovascular risk factors and co-morbidities}

STEMI is a disorder associated with multiple cardiovascular risk factors and co-morbidities, including hypertension, hyperlipidemia, diabetes, and aging.

Experimental and clinical evidence suggest that these co-morbidities induce alterations in myocardial cellular signalling cascades, thereby affecting both the sensitivity to IRI and the response to a particular cardioprotective strategy $[44,45]$.

Many examples can be found in experimental and clinical studies to illustrate this fact. For instance, hyperlipidemia is associated with the loss of cardioprotection by IPC in rabbits and rats[46,47], as well as in patients who underwent elective PCI [48,49]. Hypertension has been associated with the loss of effect of IPOST in rats [50] as well as with the attenuation of the prodromal angina effect in patients with an anterior STEMI [51]. Diabetes mellitus makes the heart more susceptible to IRI and less sensitive to the cardioprotective effect of IPC and IPOST [45,52-54]. In the same line, the benefits of prodromal angina on IS reduction has been blunted in diabetic patients presenting with anterior STEMI [55]. Finally, aging changes both the pharmacokinetics and pharmacodynamics of cardiovascular drugs[56] as well as affects the susceptibility to be protected[45]. As demonstrated in other co-morbidities, the cardioprotective effect of angina in the 24 hours before AMI is lost in elderly patients [57].

\subsubsection{Concomitant chronic medication}

The use of concomitant chronic medication prior to the STEMI might have an important influence in the final outcome, by either blocking or inducing cardioprotection themselves. 
Aspirin and statins are widely used to prevent cardiovascular events in primary prevention, increasing the likelihood of STEMI patients to be on these drugs before the ischemic episode. Interestingly, long-term statin therapy before PPCI has been associated with smaller IS and higher myocardial salvage[58].

Anti-diabetic medication deserves special attention, not only due to their increased use in STEMI patients but also because of their potential deleterious effects on cardiac tissue response. Whilst some anti-diabetics such as sulfonylureas may further impair IRI damage in diabetic patients[53], several experimental studies have suggested that metformin and dipeptidyl peptidase-4inhibitor drugs protect against IRI[59,60].

The sodium-glucose cotransporter 2 inhibitors, when administered alongside the standard care, has been recently shown to reduce cardiovascular death in patients with type 2 diabetes, making this class of drug an interesting target to be studied in the context of cardioprotection[61].

\subsubsection{Concomitant acute adjunctive medication during STEMI}

Many standard interventions in clinical practice may either attenuate IS or potentially reduce patient morbidity and mortality, making it increasingly difficult to successfully translate newer cardioprotective interventions.

Some coronary strategies might blunt the effect of any other intervention being tested - eg technical improvements in catheterization, stenting, distal protection, and thrombus aspiration; may help minimising the extent of injury caused during the interventions [39].

Aspirin, surprisingly, does not seem to protect when administered acutely[62] and its interaction with other drugs may even have a deleterious effect. For example, it has been found that low-doses of aspirin administered before reperfusion abolish the IS-limiting effect of morphine[62] as well as blunting the cardioprotective effect of atorvastatin in rats[63]. However, clinical benefits are augmented by supplementing aspirin with new antiplatelet agents such as clopidogrel, ticagrelor, or prasugrel[64-66]. Their clinical benefits have mainly been attributed to their antiplatelet effect, 
although an increasing body of evidence shows their important role on IS reduction [67] via mechanisms involving nitric oxide and adenosine $[15,68]$.

Anticoagulants are another class of medication widely used in STEMI patients and should be considered when interpreting RCT on cardioprotection. On one hand, heparin may have cardioprotective effects independently of its antithrombin mechanism[69,70], but may potentially mitigate further protective effects. On the other hand, heparin has been associated with reduction of future cardiovascular events[71,72], making it increasingly difficult to detect potential clinical benefits. The use of other anticoagulants, such as bivalirudin, may also an impact on adverse clinical events reduction[73,74].

Intravenous morphine administration is recommended by guidelines for pain relief in patients with active ischemia[75]. Opioids such as morphine have been shown to protect the heart and limit IS in various animal models[76], their impact in STEMI patients is as complex as unpredictable given its effect in delaying the availability of other orally administered drugs[77] although this has been disputed in a few recent paper [78,79].

\subsubsection{Major confounding factors after reperfusion}

Overall, event rates have dropped in STEMI patients and, as evidence-based medicine has grown, it has become increasingly difficult to demonstrate incremental benefit beyond that which has already been achieved. For instance, early mortality of STEMI patients has decreased from $20 \%$ in the late 1980 s to $5 \%$ in $2008[80,81]$, although national registries have shown variation across regions[82]. Similarly, late mortality has also experienced great changes, largely falling over time in those STEMI patients who have undergone PPCI[42].

The main consequence of this huge improvement over the years is that very large sample sizes on RCT are now required to demonstrate that a new treatment improves clinical outcomes[42].

The significant improvement observed in mortality may be attributable in a large part to the use of chronic cardiovascular medications after STEMI[83]. These secondary prevention therapies, such as angiotensin-converting enzyme inhibitors, aldosterone antagonists, $\beta$-blockers, and statins have 
sizeably improved patient prognosis[84], making it increasingly difficult to add clinical benefits on top of contemporary state-of-the-art therapy.

In spite of these improvements, mortality in post-STEMI patients still remains high and there is no evidence that a plateau on clinical outcomes improvement has been achieved. Moreover, morbidity of post-STEMI survivors has increased, resulting in a higher prevalence of patients with significantly impaired LVEF and subsequent chronic heart failure. Both mortality and morbidity consequences of IRI are an unmet socioeconomic burden that needs to be addressed with the development of further and better cardioprotective strategies.

\section{Looking towards the future - summary}

Morbidity and mortality after a STEMI still remain significant. The development of new strategies for cardioprotection which can further reduce myocardial IS and improve clinical outcomes is still an unmet need. Further efforts are required to address the gaps in the pre-clinical setting, in the use of surrogate endpoints, in designing clinical outcomes studies as well as in testing the therapies in the complex clinical setting. Tackling these gaps might increase the chances to successfully translate cardioprotective therapies, improving both post-STEMI heart failure and cardiovascular death rates. 
Acknowledgements

None. 


\section{References}

[1] E.C. Keeley, J.A. Boura, C.L. Grines, Primary angioplasty versus intravenous thrombolytic therapy for acute myocardial infarction: a quantitative review of 23 randomised trials., Lancet. 361 (2003) 13-20. doi:10.1016/S0140-6736(03)12113-7.

[2] D.M. Yellon, D.J. Hausenloy, Myocardial reperfusion injury., N. Engl. J. Med. 357 (2007) 1121-35. doi:10.1056/NEJMra071667.

[3] P.R. Maroko, J.K. Kjekshus, B.E. Sobel, T. Watanabe, J.W. Covell, J. Ross, et al., Factors influencing infarct size following experimental coronary artery occlusions., Circulation. 43 (1971) 67-82.

[4] G. Heusch, Cardioprotection : chances and challenges of its translation, Lancet. 381 (2013) 166-175. doi:10.1016/S0140-6736(12)60916-7.

[5] S. Lecour, H.E. Bøtker, G. Condorelli, S.M. Davidson, D. Garcia-Dorado, F.B. Engel, et al., ESC working group cellular biology of the heart: position paper: improving the preclinical assessment of novel cardioprotective therapies., Cardiovasc. Res. 104 (2014) 399-411. doi:10.1093/cvr/cvu225.

[6] X. Rossello, A.R. Hall, R.M. Bell, D.M. Yellon, Characterization of the Langendorff Perfused Isolated Mouse Heart Model of Global Ischemia-Reperfusion Injury: Impact of Ischemia and Reperfusion Length on Infarct Size and LDH Release, J. Cardiovasc. Pharmacol. Ther. (2015) 1074248415604462-. doi:10.1177/1074248415604462.

[7] R. Fernández-Jiménez, J. Sánchez-González, J. Agüero, J. García-Prieto, G.J. López-Martín, J.M. García-Ruiz, et al., Myocardial Edema After Ischemia/Reperfusion Is Not Stable and Follows a Bimodal Pattern, J. Am. Coll. Cardiol. 65 (2015) 315-323. doi:10.1016/j.jacc.2014.11.004.

[8] T.F. Lüscher, The bumpy road to evidence: why many research findings are lost in translation., Eur. Heart J. 34 (2013) 3329-35. doi:10.1093/eurheartj/eht396. 
[9] S.P. Jones, X.-L. Tang, Y. Guo, C. Steenbergen, D.J. Lefer, R.C. Kukreja, et al., The NHLBIsponsored Consortium for preclinicAl assESsment of cARdioprotective therapies (CAESAR): a new paradigm for rigorous, accurate, and reproducible evaluation of putative infarct-sparing interventions in mice, rabbits, and pigs., Circ. Res. 116 (2015) 572-86. doi:10.1161/CIRCRESAHA.116.305462.

[10] S.J. Pocock, B.J. Gersh, Do Current Clinical Trials Meet Society’s Needs?, J. Am. Coll. Cardiol. 64 (2014) 1615-1628. doi:10.1016/j.jacc.2014.08.008.

[11] X. Rossello, S.J. Pocock, D.G. Julian, Long-Term Use of Cardiovascular Drugs, J. Am. Coll. Cardiol. 66 (2015) 1273-1285. doi:10.1016/j.jacc.2015.07.018.

[12] X.-M. Yang, L. Cui, A. Alhammouri, J.M. Downey, M. V Cohen, Triple therapy greatly increases myocardial salvage during ischemia/reperfusion in the in situ rat heart., Cardiovasc. Drugs Ther. 27 (2013) 403-12. doi:10.1007/s10557-013-6474-9.

[13] I. Eitel, T. Stiermaier, K.P. Rommel, G. Fuernau, M. Sandri, N. Mangner, et al., Cardioprotection by combined intrahospital remote ischaemic perconditioning and postconditioning in ST-elevation myocardial infarction: the randomized LIPSIA CONDITIONING trial., Eur. Heart J. (2015). doi:10.1093/eurheartj/ehv463.

[14] R.M. Bell, S.P. Kunuthur, C. Hendry, D. Bruce-Hickman, S. Davidson, D.M. Yellon, Matrix metalloproteinase inhibition protects CyPD knockout mice independently of RISK/mPTP signalling: a parallel pathway to protection., Basic Res. Cardiol. 108 (2013) 331. doi:10.1007/s00395-013-0331-7.

[15] M. V Cohen, J.M. Downey, Signalling pathways and mechanisms of protection in pre- and postconditioning: historical perspective and lessons for the future., Br. J. Pharmacol. 172 (2015) 1913-32. doi:10.1111/bph.12903.

[16] R. Bolli, L. Becker, G. Gross, R. Mentzer, D. Balshaw, D.A. Lathrop, Myocardial protection at a crossroads: the need for translation into clinical therapy., Circ. Res. 95 (2004) 125-34. doi:10.1161/01.RES.0000137171.97172.d7 
[17] R. Bolli, Reflections on the Irreproducibility of Scientific Papers., Circ. Res. 117 (2015) 6656. doi:10.1161/CIRCRESAHA.115.307496.

[18] K.E. Wever, C.R. Hooijmans, N.P. Riksen, T.B. Sterenborg, E.S. Sena, M. Ritskes-Hoitinga, et al., Determinants of the Efficacy of Cardiac Ischemic Preconditioning: A Systematic Review and Meta-Analysis of Animal Studies., PLoS One. 10 (2015) e0142021. doi:10.1371/journal.pone.0142021.

[19] W.Y. Lim, C.M. Messow, C. Berry, Cyclosporin variably and inconsistently reduces infarct size in experimental models of reperfused myocardial infarction: a systematic review and meta-analysis., Br. J. Pharmacol. 165 (2012) 2034-43. doi:10.1111/j.1476-5381.2011.01691.x.

[20] H. Bulluck, A. Sirker, Y.K. Loke, D. Garcia-Dorado, D.J. Hausenloy, Clinical benefit of adenosine as an adjunct to reperfusion in ST-elevation myocardial infarction patients: An updated meta-analysis of randomized controlled trials., Int. J. Cardiol. 202 (2016) 228-37. doi:10.1016/j.ijcard.2015.09.005.

[21] C. Kilkenny, W.J. Browne, I.C. Cuthill, M. Emerson, D.G. Altman, Improving bioscience research reporting: the ARRIVE guidelines for reporting animal research., PLoS Biol. 8 (2010) e1000412. doi:10.1371/journal.pbio.1000412.

[22] B. Ibáñez, G. Heusch, M. Ovize, F. Van de Werf, Evolving Therapies for Myocardial Ischemia/Reperfusion Injury., J. Am. Coll. Cardiol. 65 (2015) 1454-1471. doi:10.1016/j.jacc.2015.02.032.

[23] W.S. Weintraub, T.F. Lüscher, S. Pocock, The perils of surrogate endpoints., Eur. Heart J. 36 (2015) 2212-8. doi:10.1093/eurheartj/ehv164.

[24] M. Domanski, S. Pocock, C. Bernaud, J. Borer, N. Geller, J. Revkin, et al., Surrogate endpoints in randomized cardiovascular clinical trials., Fundam. Clin. Pharmacol. 25 (2011) 411-3. doi:10.1111/j.1472-8206.2010.00865.x.

[25] H. Bulluck, D.M. Yellon, D.J. Hausenloy, Reducing myocardial infarct size: challenges and 
future opportunities., Heart. (2015). doi:10.1136/heartjnl-2015-307855.

[26] J. Lønborg, H. Kelbæk, N. Vejlstrup, H.E. Bøtker, W.Y. Kim, L. Holmvang, et al., Exenatide reduces final infarct size in patients with ST-segment-elevation myocardial infarction and short-duration of ischemia., Circ. Cardiovasc. Interv. 5 (2012) 288-95. doi:10.1161/CIRCINTERVENTIONS.112.968388.

[27] G. De Luca, H. Suryapranata, J.P. Ottervanger, E.M. Antman, Time delay to treatment and mortality in primary angioplasty for acute myocardial infarction: every minute of delay counts., Circulation. 109 (2004) 1223-5. doi:10.1161/01.CIR.0000121424.76486.20.

[28] B.J. Gersh, G.W. Stone, H.D. White, D.R. Holmes, Pharmacological facilitation of primary percutaneous coronary intervention for acute myocardial infarction: is the slope of the curve the shape of the future?, JAMA. 293 (2005) 979-86. doi:10.1001/jama.293.8.979.

[29] T. Miura, T. Miki, Limitation of myocardial infarct size in the clinical setting: current status and challenges in translating animal experiments into clinical therapy., Basic Res. Cardiol. 103 (2008) 501-13. doi:10.1007/s00395-008-0743-y.

[30] P.M. Rothwell, External validity of randomised controlled trials: "to whom do the results of this trial apply?"., Lancet. 365 82-93. doi:10.1016/S0140-6736(04)17670-8.

[31] B. Ibanez, C. Macaya, V. Sánchez-Brunete, G. Pizarro, L. Fernández-Friera, A. Mateos, et al., Effect of early metoprolol on infarct size in ST-segment-elevation myocardial infarction patients undergoing primary percutaneous coronary intervention: the Effect of Metoprolol in Cardioprotection During an Acute Myocardial Infarction (METOCARD-CNIC) tri, Circulation. 128 (2013) 1495-503. doi:10.1161/CIRCULATIONAHA.113.003653.

[32] V. Roolvink, B. Ibanez, J.P. Ottervanger, G. Pizarro, N. van Royen, A. Mateos, et al., Early Administration of intravenous Beta blockers in patients with ST-elevation myocardial infarction before primary PCI., J. Am. Coll. Cardiol. (2016). doi:10.1016/j.jacc.2016.03.522.

[33] H.E. Bøtker, R. Kharbanda, M.R. Schmidt, M. Bøttcher, A.K. Kaltoft, C.J. Terkelsen, et al., 
Remote ischaemic conditioning before hospital admission, as a complement to angioplasty, and effect on myocardial salvage in patients with acute myocardial infarction: a randomised trial, Lancet. 375 (2010) 727-734. doi:10.1016/S0140-6736(09)62001-8.

[34] H.P. Selker, J.R. Beshansky, P.R. Sheehan, J.M. Massaro, J.L. Griffith, R.B. D’Agostino, et al., Out-of-hospital administration of intravenous glucose-insulin-potassium in patients with suspected acute coronary syndromes: the IMMEDIATE randomized controlled trial., JAMA. 307 (2012) 1925-33. doi:10.1001/jama.2012.426.

[35] G. Pizarro, L. Fernández-Friera, V. Fuster, R. Fernández-Jiménez, J.M. García-Ruiz, A. García-Álvarez, et al., Long-term benefit of early pre-reperfusion metoprolol administration in patients with acute myocardial infarction: results from the METOCARD-CNIC trial (Effect of Metoprolol in Cardioprotection During an Acute Myocardial Infarction)., J. Am. Coll. Cardiol. 63 (2014) 2356-62. doi:10.1016/j.jacc.2014.03.014.

[36] J.M. García-Ruiz, R. Fernández-Jiménez, A. García-Alvarez, G. Pizarro, C. Galán-Arriola, L. Fernández-Friera, et al., Impact of the Timing of Metoprolol Administration During STEMI on Infarct Size and Ventricular Function., J. Am. Coll. Cardiol. 67 (2016) 2093-2104. doi:10.1016/j.jacc.2016.02.050.

[37] K. Pryds, C.J. Terkelsen, A.D. Sloth, K. Munk, S.S. Nielsen, M.R. Schmidt, et al., Remote ischaemic conditioning and healthcare system delay in patients with ST-segment elevation myocardial infarction, Heart. (2016) heartjnl-2015-308980. doi:10.1136/heartjnl-2015308980.

[38] S.J. Pocock, T.C. Clayton, G.W. Stone, Design of Major Randomized Trials, J. Am. Coll. Cardiol. 66 (2015) 2757-2766. doi:10.1016/j.jacc.2015.10.036.

[39] M. Ovize, H. Thibault, K. Przyklenk, Myocardial conditioning: Opportunities for clinical translation, Circ. Res. 113 (2013) 439-450. doi:10.1161/CIRCRESAHA.113.300764.

[40] T.-T. Cung, O. Morel, G. Cayla, G. Rioufol, D. Garcia-Dorado, D. Angoulvant, et al., Cyclosporine before PCI in Patients with Acute Myocardial Infarction, N. Engl. J. Med. 373 
(2015) 150830000044009. doi:10.1056/NEJMoa1505489.

[41] D. Wang, S. Pocock, A win ratio approach to comparing continuous non-normal outcomes in clinical trials., Pharm. Stat. (2016). doi:10.1002/pst.1743.

[42] F. Pedersen, V. Butrymovich, H. Kelbæk, K. Wachtell, S. Helqvist, J. Kastrup, et al., Shortand long-term cause of death in patients treated with primary PCI for STEMI., J. Am. Coll. Cardiol. 64 (2014) 2101-8. doi:10.1016/j.jacc.2014.08.037.

[43] An international randomized trial comparing four thrombolytic strategies for acute myocardial infarction. The GUSTO investigators., N. Engl. J. Med. 329 (1993) 673-82. doi:10.1056/NEJM199309023291001.

[44] L. Schwartz Longacre, R.A. Kloner, A.E. Arai, C.P. Baines, R. Bolli, E. Braunwald, et al., New horizons in cardioprotection: recommendations from the 2010 National Heart, Lung, and Blood Institute Workshop., Circulation. 124 (2011) 1172-9. doi:10.1161/CIRCULATIONAHA.111.032698.

[45] H.J. Whittington, I. Harding, C.I.M. Stephenson, R. Bell, D.J. Hausenloy, M.M. Mocanu, et al., Cardioprotection in the aging, diabetic heart: the loss of protective Akt signalling., Cardiovasc. Res. 99 (2013) 694-704. doi:10.1093/cvr/cvt140.

[46] Z. Szilvassy, P. Ferdinandy, I. Nagy, I. Jakab, M. Koltai, The effect of continuous versus intermittent treatment with transdermal nitroglycerin on pacing-induced preconditioning in conscious rabbits, Br. J. Pharmacol. 121 (1997) 491-496. doi:10.1038/sj.bjp.0701163.

[47] P. Ferdinandy, Z. Szilvássy, L.I. Horváth, T. Csont, C. Csonka, E. Nagy, et al., Loss of pacinginduced preconditioning in rat hearts: role of nitric oxide and cholesterol-enriched diet., J. Mol. Cell. Cardiol. 29 (1997) 3321-33. doi:10.1006/jmcc.1997.0557.

[48] Z.S. Kyriakides, S. Psychari, E.K. Iliodromitis, T.M. Kolettis, E. Sbarouni, D.T. Kremastinos, Hyperlipidemia prevents the expected reduction of myocardial ischemia on repeated balloon inflations during angioplasty., Chest. 121 (2002) 1211-5. 
[49] I. Ungi, Hypercholesterolemia Attenuates the Anti-ischemic Effect of Preconditioning During Coronary Angioplasty\&lt;xref rid=“AFF1”\&gt;\&lt;sup\&gt;*\&lt;/sup\&gt;\&lt;/xref\&gt;, CHEST J. 128 (2005) 1623. doi:10.1378/chest.128.3.1623.

[50] C. Penna, F. Tullio, F. Moro, A. Folino, A. Merlino, P. Pagliaro, Effects of a protocol of ischemic postconditioning and/or captopril in hearts of normotensive and hypertensive rats., Basic Res. Cardiol. 105 (2010) 181-92. doi:10.1007/s00395-009-0075-6.

[51] T. Takeuchi, Y. Ishii, K. Kikuchi, N. Hasebe, Ischemic preconditioning effect of prodromal angina is attenuated in acute myocardial infarction patients with hypertensive left ventricular hypertrophy., Circ. J. 75 (2011) 1192-9.

[52] T. Miki, T. Itoh, D. Sunaga, T. Miura, Effects of diabetes on myocardial infarct size and cardioprotection by preconditioning and postconditioning, Cardiovasc. Diabetol. 11 (2012) 67. doi:10.1186/1475-2840-11-67.

[53] P. Ferdinandy, R. Schulz, G.F. Baxter, Interaction of cardiovascular risk factors with myocardial ischemia/reperfusion injury, preconditioning, and postconditioning., Pharmacol. Rev. 59 (2007) 418-58. doi:10.1124/pr.107.06002.

[54] V. Sivaraman, D.J. Hausenloy, A.M. Wynne, D.M. Yellon, Preconditioning the diabetic human myocardium., J. Cell. Mol. Med. 14 (2010) 1740-6. doi:10.1111/j.15824934.2009.00796.x.

[55] M. Ishihara, I. Inoue, T. Kawagoe, Y. Shimatani, S. Kurisu, K. Nishioka, et al., Diabetes mellitus prevents ischemic preconditioning in patients with a first acute anterior wall myocardial infarction., J. Am. Coll. Cardiol. 38 (2001) 1007-11.

[56] O. Mukhtar, S.H. Jackson, Drug therapies in older adults (part 1), Clin. Med. (Northfield. Il). 15 (2015) 47-53. doi:10.7861/clinmedicine.15-1-47.

[57] M. Ishihara, H. Sato, H. Tateishi, T. Kawagoe, Y. Shimatani, K. Ueda, et al., Beneficial effect of prodromal angina pectoris is lost in elderly patients with acute myocardial infarction., Am. 
Heart J. 139 (2000) 881-8.

[58] G. Marenzi, N. Cosentino, S. Cortinovis, V. Milazzo, M. Rubino, A. Cabiati, et al., Myocardial Infarct Size in Patients on Long-Term Statin Therapy Undergoing Primary Percutaneous Coronary Intervention for ST-Elevation Myocardial Infarction., Am. J. Cardiol. 116 (2015) 1791-7. doi:10.1016/j.amjcard.2015.09.016.

[59] H.J. Whittington, A.R. Hall, C.P. McLaughlin, D.J. Hausenloy, D.M. Yellon, M.M. Mocanu, Chronic metformin associated cardioprotection against infarction: not just a glucose lowering phenomenon., Cardiovasc. Drugs Ther. 27 (2013) 5-16. doi:10.1007/s10557-012-6425-x.

[60] D.J. Hausenloy, H.J. Whittington, A.M. Wynne, S.S. Begum, L. Theodorou, N. Riksen, et al., Dipeptidyl peptidase-4 inhibitors and GLP-1 reduce myocardial infarct size in a glucosedependent manner., Cardiovasc. Diabetol. 12 (2013) 154. doi:10.1186/1475-2840-12-154.

[61] B. Zinman, C. Wanner, J.M. Lachin, D. Fitchett, E. Bluhmki, S. Hantel, et al., Empagliflozin, Cardiovascular Outcomes, and Mortality in Type 2 Diabetes, N. Engl. J. Med. 373 (2015) 150917085022006. doi:10.1056/NEJMoa1504720.

[62] E.R. Gross, A.K. Hsu, G.J. Gross, Acute aspirin treatment abolishes, whereas acute ibuprofen treatment enhances morphine-induced cardioprotection: role of 12-lipoxygenase., J.

Pharmacol. Exp. Ther. 310 (2004) 185-91. doi:10.1124/jpet.103.064667.

[63] Y. Birnbaum, Y. Lin, Y. Ye, J.D. Martinez, M.-H. Huang, C.Y. Lui, et al., Aspirin before reperfusion blunts the infarct size limiting effect of atorvastatin., Am. J. Physiol. Heart Circ. Physiol. 292 (2007) H2891-7. doi:10.1152/ajpheart.01269.2006.

[64] M.S. Sabatine, C.P. Cannon, C.M. Gibson, J.L. López-Sendón, G. Montalescot, P. Theroux, et al., Addition of clopidogrel to aspirin and fibrinolytic therapy for myocardial infarction with ST-segment elevation., N. Engl. J. Med. 352 (2005) 1179-89. doi:10.1056/NEJMoa050522.

[65] G. Montalescot, S.D. Wiviott, E. Braunwald, S.A. Murphy, C.M. Gibson, C.H. McCabe, et al., Prasugrel compared with clopidogrel in patients undergoing percutaneous coronary 
intervention for ST-elevation myocardial infarction (TRITON-TIMI 38): double-blind, randomised controlled trial., Lancet (London, England). 373 (2009) 723-31. doi:10.1016/S0140-6736(09)60441-4.

[66] P.G. Steg, S. James, R.A. Harrington, D. Ardissino, R.C. Becker, C.P. Cannon, et al., Ticagrelor versus clopidogrel in patients with ST-elevation acute coronary syndromes intended for reperfusion with primary percutaneous coronary intervention: A Platelet Inhibition and Patient Outcomes (PLATO) trial subgroup analysis., Circulation. 122 (2010) 2131-41. doi:10.1161/CIRCULATIONAHA.109.927582.

[67] M. V Cohen, J.M. Downey, Combined cardioprotectant and antithrombotic actions of platelet P2Y12 receptor antagonists in acute coronary syndrome: just what the doctor ordered., J. Cardiovasc. Pharmacol. Ther. 19 (2014) 179-90. doi:10.1177/1074248413508465.

[68] R.M. Bell, V. Sivaraman, S.P. Kunuthur, M. V Cohen, J.M. Downey, D.M. Yellon, Cardioprotective Properties of the Platelet P2Y12 Receptor Inhibitor, Cangrelor: Protective in Diabetics and Reliant Upon the Presence of Blood., Cardiovasc. Drugs Ther. 29 (2015) 415-8. doi:10.1007/s10557-015-6609-2.

[69] G.S. Friedrichs, K.S. Kilgore, P.J. Manley, M.R. Gralinski, B.R. Lucchesi, Effects of heparin and $\mathrm{N}$-acetyl heparin on ischemia/reperfusion-induced alterations in myocardial function in the rabbit isolated heart., Circ. Res. 75 (1994) 701-10.

[70] S.C. Black, M.R. Gralinski, G.S. Friedrichs, K.S. Kilgore, E.M. Driscoll, B.R. Lucchesi, Cardioprotective effects of heparin or $\mathrm{N}$-acetylheparin in an in vivo model of myocardial ischaemic and reperfusion injury, Cardiovasc. Res. 29 (1995) 629-636. doi:10.1016/S00086363(96)88632-9

[71] E.M. Antman, D.A. Morrow, C.H. McCabe, S.A. Murphy, M. Ruda, Z. Sadowski, et al., Enoxaparin versus unfractionated heparin with fibrinolysis for ST-elevation myocardial infarction., N. Engl. J. Med. 354 (2006) 1477-88. doi:10.1056/NEJMoa060898.

[72] G. Montalescot, U. Zeymer, J. Silvain, B. Boulanger, M. Cohen, P. Goldstein, et al., 
Intravenous enoxaparin or unfractionated heparin in primary percutaneous coronary intervention for ST-elevation myocardial infarction: the international randomised open-label ATOLL trial., Lancet. 378 (2011) 693-703. doi:10.1016/S0140-6736(11)60876-3.

[73] R. Mehran, A.J. Lansky, B. Witzenbichler, G. Guagliumi, J.Z. Peruga, B.R. Brodie, et al., Bivalirudin in patients undergoing primary angioplasty for acute myocardial infarction (HORIZONS-AMI): 1-year results of a randomised controlled trial., Lancet (London, England). 374 (2009) 1149-59. doi:10.1016/S0140-6736(09)61484-7.

[74] P.G. Steg, A. van 't Hof, C.W. Hamm, P. Clemmensen, F. Lapostolle, P. Coste, et al., Bivalirudin started during emergency transport for primary PCI., N. Engl. J. Med. 369 (2013) 2207-17. doi:10.1056/NEJMoa1311096.

[75] P.T. O'Gara, F.G. Kushner, D.D. Ascheim, D.E. Casey, M.K. Chung, J.A. de Lemos, et al., 2013 ACCF/AHA guideline for the management of ST-elevation myocardial infarction: a report of the American College of Cardiology Foundation/American Heart Association Task Force on Practice Guidelines., J. Am. Coll. Cardiol. 61 (2013) e78-140. doi:10.1016/j.jacc.2012.11.019.

[76] S.P. Bell, M.N. Sack, A. Patel, L.H. Opie, D.M. Yellon, Delta opioid receptor stimulation mimics ischemic preconditioning in human heart muscle., J. Am. Coll. Cardiol. 36 (2000) 2296-302.

[77] G.D. Birnbaum, I. Birnbaum, Y. Ye, Y. Birnbaum, Statin-Induced Cardioprotection Against Ischemia-Reperfusion Injury: Potential Drug-Drug Interactions. Lesson to be Learnt by Translating Results from Animal Models to the Clinical Settings., Cardiovasc. Drugs Ther. (2015). doi:10.1007/s10557-015-6615-4.

[78] E. Puymirat, L. Lamhaut, N. Bonnet, N. Aissaoui, P. Henry, G. Cayla, et al., Correlates of prehospital morphine use in ST-elevation myocardial infarction patients and its association with in-hospital outcomes and long-term mortality: the FAST-MI (French Registry of Acute STelevation and non-ST-elevation Myocardial Infarction) pr, Eur. Heart J. 37 (2016) 1063-71. 
doi:10.1093/eurheartj/ehv567.

[79] J. Kubica, P. Adamski, M. Ostrowska, J. Sikora, J.M. Kubica, W.D. Sroka, et al., Morphine delays and attenuates ticagrelor exposure and action in patients with myocardial infarction: the randomized, double-blind, placebo-controlled IMPRESSION trial., Eur. Heart J. 37 (2016) 245-52. doi:10.1093/eurheartj/ehv547.

[80] D.S. Menees, E.D. Peterson, Y. Wang, J.P. Curtis, J.C. Messenger, J.S. Rumsfeld, et al., Doorto-balloon time and mortality among patients undergoing primary PCI., N. Engl. J. Med. 369 (2013) 901-9. doi:10.1056/NEJMoa1208200.

[81] Z.J. Eapen, W.H.W. Tang, G.M. Felker, A.F. Hernandez, K.W. Mahaffey, A.M. Lincoff, et al., Defining heart failure end points in ST-segment elevation myocardial infarction trials: integrating past experiences to chart a path forward., Circ. Cardiovasc. Qual. Outcomes. 5 (2012) 594-600. doi:10.1161/CIRCOUTCOMES.112.966150.

[82] L. Mandelzweig, The second Euro Heart Survey on acute coronary syndromes: characteristics, treatment, and outcome of patients with ACS in Europe and the Mediterranean Basin in 2004, Eur. Heart J. 27 (2006) 2285-2293. doi:10.1093/eurheartj/ehl196.

[83] S. Setoguchi, R.J. Glynn, J. Avorn, M.A. Mittleman, R. Levin, W.C. Winkelmayer, Improvements in long-term mortality after myocardial infarction and increased use of cardiovascular drugs after discharge: a 10-year trend analysis., J. Am. Coll. Cardiol. 51 (2008) 1247-54. doi:10.1016/j.jacc.2007.10.063.

[84] T. Jernberg, P. Hasvold, M. Henriksson, H. Hjelm, M. Thuresson, M. Janzon, Cardiovascular risk in post-myocardial infarction patients: nationwide real world data demonstrate the importance of a long-term perspective., Eur. Heart J. 36 (2015) 1163-70. doi:10.1093/eurheartj/ehu505.

[85] T. Mizumura, K. Nithipatikom, G.J. Gross, Infarct size-reducing effect of nicorandil is mediated by the KATP channel but not by its nitrate-like properties in dogs., Cardiovasc. Res. 32 (1996) 274-85. 
[86] M. Kitakaze, M. Asakura, J. Kim, Y. Shintani, H. Asanuma, T. Hamasaki, et al., Human atrial natriuretic peptide and nicorandil as adjuncts to reperfusion treatment for acute myocardial infarction (J-WIND): two randomised trials., Lancet. 370 (2007) 1483-93. doi:10.1016/S01406736(07)61634-1.

[87] A.N. Grossman, L.H. Opie, J.R. Beshansky, J.S. Ingwall, C.E. Rackley, H.P. Selker, Glucoseinsulin-potassium revived: current status in acute coronary syndromes and the energy-depleted heart., Circulation. 127 (2013) 1040-8. doi:10.1161/CIRCULATIONAHA.112.130625.

[88] S.R. Mehta, S. Yusuf, R. Díaz, J. Zhu, P. Pais, D. Xavier, et al., Effect of glucose-insulinpotassium infusion on mortality in patients with acute ST-segment elevation myocardial infarction: the CREATE-ECLA randomized controlled trial., JAMA. 293 (2005) 437-46. doi:10.1001/jama.293.4.437.

[89] X.-M. Yang, S. Philipp, J.M. Downey, M. V Cohen, Atrial natriuretic peptide administered just prior to reperfusion limits infarction in rabbit hearts., Basic Res. Cardiol. 101 (2006) 3118. doi:10.1007/s00395-006-0587-2.

[90] G.S. Liu, J. Thornton, D.M. Van Winkle, A.W. Stanley, R.A. Olsson, J.M. Downey, Protection against infarction afforded by preconditioning is mediated by A1 adenosine receptors in rabbit heart., Circulation. 84 (1991) 350-6.

[91] K.W. Mahaffey, J.A. Puma, N.A. Barbagelata, M.F. DiCarli, M.A. Leesar, K.F. Browne, et al., Adenosine as an adjunct to thrombolytic therapy for acute myocardial infarction: results of a multicenter, randomized, placebo-controlled trial: the Acute Myocardial Infarction STudy of ADenosine (AMISTAD) trial., J. Am. Coll. Cardiol. 34 (1999) 1711-20.

[92] D. Garcia-Dorado, B. García-Del-Blanco, I. Otaegui, J. Rodríguez-Palomares, V. Pineda, F. Gimeno, et al., Intracoronary injection of adenosine before reperfusion in patients with STsegment elevation myocardial infarction: A randomized controlled clinical trial., Int. J. Cardiol. 177 (2014) 935-941. doi:10.1016/j.ijcard.2014.09.203.

[93] G. Heusch, Treatment of Myocardial Ischemia/Reperfusion Injury by Ischemic and 
Pharmacological Postconditioning., Compr. Physiol. 5 (2015) 1123-45.

doi:10.1002/cphy.c140075.

[94] H. Thibault, C. Piot, P. Staat, L. Bontemps, C. Sportouch, G. Rioufol, et al., Long-term benefit of postconditioning., Circulation. 117 (2008) 1037-44.

doi:10.1161/CIRCULATIONAHA.107.729780.

[95] P. Staat, G. Rioufol, C. Piot, Y. Cottin, T.T. Cung, I. L'Huillier, et al., Postconditioning the human heart., Circulation. 112 (2005) 2143-8.

doi:10.1161/CIRCULATIONAHA.105.558122.

[96] G. Heusch, H.E. Bøtker, K. Przyklenk, A. Redington, D. Yellon, Remote ischemic conditioning., J. Am. Coll. Cardiol. 65 (2015) 177-95. doi:10.1016/j.jacc.2014.10.031.

[97] D.J. Hausenloy, R. Kharbanda, M. Rahbek Schmidt, U.K. Møller, J. Ravkilde, L. Okkels Jensen, et al., Effect of remote ischaemic conditioning on clinical outcomes in patients presenting with an ST-segment elevation myocardial infarction undergoing primary percutaneous coronary intervention., Eur. Heart J. 36 (2015) 1846-8.

[98] C. Piot, P. Croisille, P. Staat, H. Thibault, G. Rioufol, N. Mewton, et al., Effect of cyclosporine on reperfusion injury in acute myocardial infarction., N. Engl. J. Med. 359 (2008) 473-81. doi:10.1056/NEJMoa071142.

[99] F. Ottani, R. Latini, L. Staszewsky, L. La Vecchia, N. Locuratolo, M. Sicuro, et al., Cyclosporine A in Reperfused Myocardial Infarction: The Multicenter, Controlled, OpenLabel CYCLE Trial., J. Am. Coll. Cardiol. 67 (2016) 365-74. doi:10.1016/j.jacc.2015.10.081.

[100] D.P. Sonne, T. Engstrøm, M. Treiman, Protective effects of GLP-1 analogues exendin-4 and GLP-1(9-36) amide against ischemia-reperfusion injury in rat heart., Regul. Pept. 146 (2008) 243-9. doi:10.1016/j.regpep.2007.10.001.

[101] L. Timmers, J.P.S. Henriques, D.P. V de Kleijn, J.H. Devries, H. Kemperman, P. Steendijk, et al., Exenatide reduces infarct size and improves cardiac function in a porcine model of 
ischemia and reperfusion injury., J. Am. Coll. Cardiol. 53 (2009) 501-10. doi:10.1016/j.jacc.2008.10.033.

[102] J. Lønborg, N. Vejlstrup, H. Kelbæk, H.E. Bøtker, W.Y. Kim, A.B. Mathiasen, et al., Exenatide reduces reperfusion injury in patients with ST-segment elevation myocardial infarction., Eur. Heart J. 33 (2012) 1491-9. doi:10.1093/eurheartj/ehr309.

[103] B. Ibanez, S. Prat-González, W.S. Speidl, G. Vilahur, A. Pinero, G. Cimmino, et al., Early metoprolol administration before coronary reperfusion results in increased myocardial salvage: analysis of ischemic myocardium at risk using cardiac magnetic resonance., Circulation. 115 (2007) 2909-16. doi:10.1161/CIRCULATIONAHA.106.679639.

[104] B. Ibanez, V. Fuster, Reply: early intravenous beta-blockade before primary percutaneous coronary intervention gives major benefits apparently without side effects., J. Am. Coll. Cardiol. 64 (2014) 1864-5. doi:10.1016/j.jacc.2014.08.013.

[105] D. Erlinge, A Review of Mild Hypothermia as an Adjunctive Treatment for ST-Elevation Myocardial Infarction., Ther. Hypothermia Temp. Manag. 1 (2011) 129-41. doi:10.1089/ther.2011.0008.

[106] D. Erlinge, M. Götberg, I. Lang, M. Holzer, M. Noc, P. Clemmensen, et al., Rapid endovascular catheter core cooling combined with cold saline as an adjunct to percutaneous coronary intervention for the treatment of acute myocardial infarction. The CHILL-MI trial: a randomized controlled study of the use of central venous cathete, J. Am. Coll. Cardiol. 63 (2014) 1857-65. doi:10.1016/j.jacc.2013.12.027.

[107] S. Schaller, S. Paradis, G.A. Ngoh, R. Assaly, B. Buisson, C. Drouot, et al., TRO40303, a new cardioprotective compound, inhibits mitochondrial permeability transition., J. Pharmacol. Exp. Ther. 333 (2010) 696-706. doi:10.1124/jpet.110.167486.

[108] M.J. Hansson, O. Llwyd, D. Morin, D. de Paulis, T. Arnoux, C. Gouarné, et al., Differences in the profile of protection afforded by TRO40303 and mild hypothermia in models of cardiac ischemia/reperfusion injury., Eur. J. Pharmacol. 760 (2015) 7-19. 
doi:10.1016/j.ejphar.2015.04.009.

[109] D. Atar, H. Arheden, A. Berdeaux, J.-L. Bonnet, M. Carlsson, P. Clemmensen, et al., Effect of intravenous TRO40303 as an adjunct to primary percutaneous coronary intervention for acute ST-elevation myocardial infarction: MITOCARE study results., Eur. Heart J. 36 (2015) 112-9. doi:10.1093/eurheartj/ehu331. 


\section{Tables}

\section{Table 1}

The translational journey of some specific cardioprotective therapies in STEMI patients

\begin{tabular}{|c|c|c|c|c|}
\hline $\begin{array}{l}\text { Therapeutic } \\
\text { intervention }\end{array}$ & Pre-clinical knowledge & Surrogate outcome studies & Clinical outcome results & $\begin{array}{l}\text { Potential reasons for neutral results } \\
\text { in the clinical setting }\end{array}$ \\
\hline Nicorandil & $\begin{array}{l}\text { Nicorandil given just before IRI reduced } \\
\text { IS in a dog model [85] } \\
\text { Main mechanism: combination of } \\
\text { ATP-sensitive potassium channel opener } \\
\text { and nitrate preparation }\end{array}$ & $\begin{array}{l}\text { J-WIND-KTP trial [86] tested the } \\
\text { administration of nicorandil started } \\
\text { after reperfusion, demonstrating no } \\
\text { difference in myocardial IS measured } \\
\text { using biomarkers or } 6 \text { month LVEF }\end{array}$ & No data & $\begin{array}{l}\text { - Not only anterior STEMI } \\
\text { - Treatment started after reperfusion }\end{array}$ \\
\hline $\begin{array}{l}\text { Glucose- } \\
\text { Insulin } \\
\text { Potassium }\end{array}$ & $\begin{array}{l}\text { GIK slows the progression of IRI in } \\
\text { many experimental settings [87] } \\
\text { Main mechanism: promotion of glucose } \\
\text { metabolism }\end{array}$ & $\begin{array}{l}\text { IMMEDIATE trial [34] demonstrated a } \\
\text { reduction in myocardial IS with no } \\
\text { difference in progression to myocardial } \\
\text { infarction }\end{array}$ & $\begin{array}{l}\text { CREATE-ECLA[88] } \\
\text { showed no differences in } \\
\text { mortality at } 30 \text { days }\end{array}$ & $\begin{array}{l}\text { - IV GIK infusion for } 24 \mathrm{~h} \text { started after } \\
\text { reperfusion in the majority of cases } \\
\text { - Not only anterior STEMI } \\
\text { - Prior TIMI flow grade not used as } \\
\text { selection criteria }\end{array}$ \\
\hline $\begin{array}{l}\text { Atrial } \\
\text { natriuretic } \\
\text { peptide }\end{array}$ & $\begin{array}{l}\text { ANP given just prior to reperfusion } \\
\text { reduced IS in rabbit hearts [89] } \\
\text { Main mechanism: ANP targets } \\
\text { prosurvival kinase pathways such as the } \\
\text { cGMP and RISK pathways }\end{array}$ & $\begin{array}{l}\text { J-WIND-ANP: Intravenous carperitide } \\
\text { (an ANP analogue) starting prior PPCI } \\
\text { reduced IS measured by biomarker } \\
\text { release and showed a slight increase in } \\
\text { LVEF[86] }\end{array}$ & No data & $\begin{array}{l}\text { - Further studies are needed to } \\
\text { determine whether carperitide has an } \\
\text { impact in clinical outcomes }\end{array}$ \\
\hline Adenosine & $\begin{array}{l}\text { Prior to index ischemia, adenosine } \\
\text { reduces IS in animal models of acute IRI } \\
\text { [90]. Whether it can also be effective } \\
\text { when administered at the time of } \\
\text { reperfusion is less clear. } \\
\text { Main mechanism: } \\
\text { nitric oxide and protein kinase } G \\
\end{array}$ & $\begin{array}{l}\text { AMISTAD study reported reductions } \\
\text { in IS with high-dose intravenous } \\
\text { administration[91], whilst PROMISE } \\
\text { study [92]failed to show reproduce the } \\
\text { results using lower doses of } \\
\text { intracoronary adenosine }\end{array}$ & No data & $\begin{array}{l}\text { - Doses and route of administration } \\
\text { (intravenous vs. intracoronary) }\end{array}$ \\
\hline
\end{tabular}




\begin{tabular}{|c|c|c|c|c|}
\hline $\begin{array}{l}\text { Therapeutic } \\
\text { intervention }\end{array}$ & Pre-clinical knowledge & Surrogate outcome studies & Clinical outcome results & $\begin{array}{l}\text { Potential reasons for neutral results } \\
\text { in the clinical setting }\end{array}$ \\
\hline IPOST & $\begin{array}{l}\text { IPOST has demonstrated to be capable of } \\
\text { reduce both myocardial IS and coronary } \\
\text { microvascular obstruction [93] } \\
\text { Main mechanism: } \\
\text { Delayed reversal of acidosis and } \\
\text { activation of pro-survival cascades }\end{array}$ & $\begin{array}{l}\text { Significant reduction in biomarkers } \\
\text { release, increase in LVEF and } \\
\text { reduction in myocardial IS by } \\
\text { SPECT } 94,95]\end{array}$ & $\begin{array}{l}\text { DANAMI 3-iPOST has } \\
\text { failed to demonstrate } \\
\text { clinical benefit using a } \\
\text { composite endpoint of } \\
\text { all-cause mortality and } \\
\text { hospitalization for } \\
\text { congestive heart failure * }\end{array}$ & $\begin{array}{l}\text { - Risk of coronary microembolization } \\
\text { - Potential influence of concomitant } \\
\text { co-morbidities and co-treatment on } \\
\text { the ischemic conditioning response }\end{array}$ \\
\hline RIC & $\begin{array}{l}\text { Consistent evidence among diverse } \\
\text { models and species that RIC confers } \\
\text { cytoprotection against IRI[96] } \\
\text { Main mechanism: } \\
\text { Neural and/or humoral signalling }\end{array}$ & $\begin{array}{l}\text { Increase in the myocardial salvage } \\
\text { index at } 30 \text { days when applied in the } \\
\text { ambulance [33] }\end{array}$ & $\begin{array}{l}\text { CONDI2/ERIC-PPCI } \\
\text { study [97] is expected to } \\
\text { recruit } 4300 \text { patients } \\
\text { (NCT01857414) }\end{array}$ & \\
\hline Cyclosporin & $\begin{array}{l}\text { Cyclosporin has demonstrated to reduce } \\
\text { IS in many studies, with some } \\
\text { contentious results [19] } \\
\text { Main mechanism: inhibition of MPTP } \\
\text { opening }\end{array}$ & $\begin{array}{l}\text { Significant reduction in } 72 \mathrm{~h} \text { AUC, } \\
\text { increase in LVEF and reduction in } \\
\text { myocardial IS by CMR [98], although } \\
\text { very recently the CYCLE study [99] } \\
\text { failed to demonstrate enzymatic IS } \\
\text { reduction and ST-segment resolution }\end{array}$ & $\begin{array}{l}\text { CIRCUS trial [40] failed } \\
\text { to improved clinical } \\
\text { outcomes at } 1 \text { year in } \\
\text { anterior STEMI patients }\end{array}$ & $\begin{array}{l}\text { - Total ischemic times were relatively } \\
\text { prolonged }(4.5 \mathrm{~h}) \\
\text { - Dose and route of administration }\end{array}$ \\
\hline Exenatide & $\begin{array}{l}\text { Exenatide has resulted cardioprotective } \\
\text { in both small and large animal } \\
\text { models[100,101] } \\
\text { Main mechanism: GLP-1 analogy, } \\
\text { NO/cGMP signalling pathway }\end{array}$ & $\begin{array}{l}\text { Increase in the myocardial salvage } \\
\text { index at } 90 \text { days by CMR[102] }\end{array}$ & No data & $\begin{array}{l}\text { - Further studies are needed to } \\
\text { determine whether exenatide has an } \\
\text { impact in clinical outcomes }\end{array}$ \\
\hline Metoprolol & $\begin{array}{l}\text { Metoprolol reduced myocardial IS and } \\
\text { preserve LV systolic function in a swine } \\
\text { model [103] } \\
\text { Main mechanism: unknown, although it } \\
\text { seems to extend beyond their effect on } \\
\text { hemodynamics and oxygen consumption }\end{array}$ & $\begin{array}{l}\text { METOCARD-CNIC trial [31] } \\
\text { administered in the ambulance reduced } \\
\text { IS and preserved LV systolic function } \\
\text { EARLY BAMI trial [32] has recently } \\
\text { reported that early intravenous } \\
\text { metoprolol before PPCI was not } \\
\text { associated with a reduction in infarct } \\
\text { size in a non-restricted STEMI } \\
\text { population }\end{array}$ & $\begin{array}{l}\text { Move On! Trial [104] } \\
\text { plans to investigate the } \\
\text { effect of metoprolol on } \\
\text { mortality and heart } \\
\text { failure hospitalization }\end{array}$ & $\begin{array}{l}\text { - the largest trial has been performed } \\
\text { in all AMI locations, whilst the } \\
\text { positive effects had been shown in } \\
\text { anterior infarcts } \\
\text { - the timing of drug administration } \\
\text { might be of major importance, as a } \\
\text { substudy reveals that the sooner } \\
\text { metoprolol is administered in the } \\
\text { course of infarction, the smaller is the } \\
\text { infarct and the higher the LVEF[36] }\end{array}$ \\
\hline
\end{tabular}




\begin{tabular}{|c|c|c|c|c|}
\hline $\begin{array}{l}\text { Therapeutic } \\
\text { intervention }\end{array}$ & Pre-clinical knowledge & Surrogate outcome studies & Clinical outcome results & $\begin{array}{l}\text { Potential reasons for neutral results } \\
\text { in the clinical setting }\end{array}$ \\
\hline Hypothermia & $\begin{array}{l}\text { Hypothermia can reduce IS either } \\
\text { starting before ischemia, during ischemia } \\
\text { or immediately at reperfusion [105] } \\
\text { Main mechanism: energy preservation } \\
\text { (reduction of metabolic demands) }\end{array}$ & $\begin{array}{l}\text { CHILL-MI trial [106] failed to } \\
\text { demonstrated an overall IS reduction } \\
\text { using hypothermia, although patients } \\
\text { with an anterior STEMI presenting } \\
\text { within } 4 \text { h benefited from the therapy }\end{array}$ & No data & $\begin{array}{l}\text { - the main limitation to translate the } \\
\text { therapy is the technology: further } \\
\text { devices capable of inducing } \\
\text { hypothermia at a faster rate are } \\
\text { needed }\end{array}$ \\
\hline TRO40303 & $\begin{array}{l}\text { Reduction of myocardial IS when } \\
\text { administered at time of reperfusion in } \\
\text { small-animal model[107], although } \\
\text { failing in a large-animal model[108] } \\
\text { Main mechanism: inhibition of MPTP } \\
\text { opening by attenuating ROS production }\end{array}$ & $\begin{array}{l}\text { MITOCARE study[109] failed to show } \\
\text { IS reduction and increased myocardial } \\
\text { salvage, using biomarkers and CMR } \\
\text { respectively }\end{array}$ & No data & $\begin{array}{l}\text { - Not enough pre-clinical evidence } \\
\text { - Formulation and dosage of } \\
\text { TRO40303 used in the clinical setting } \\
\text { differed from pre-clinical studies } \\
\text { - Difference between groups in TIMI- } \\
\text { flow of culprit artery after PCI (12.1\% } \\
\text { in the TRO40303-group vs } 6.3 \% \text { in } \\
\text { the placebo-group) }\end{array}$ \\
\hline
\end{tabular}

*Presented by Dr. Thomas Engstrøm at the American College of Cardiology Annual Scientific Session, Chicago, IL, April 3, 2016.

Acronyms: AMISTAD (The Acute Myocardial Infarction STudy of ADenosine); CHILL-MI (AMI: Rapid Endovascular Catheter Core Cooling Combined With Cold Saline as an Adjunct to Percutaneous Coronary Intervention for the Treatment of Acute Myocardial Infarction); CIRCUS (Cyclosporine to ImpRove Clinical oUtcome in STelevation myocardial infarction patients); CREATE-ECLA (Clinical Trial of MEtabolic Modulation in Acute Myocardial Infarction Treatment Evaluation-Estudios Cardiologicos Latinoamerica); CYCLE (CYCLosporinE A in Reperfused Acute Myocardial Infarction); DANAMI 3-iPOST (Third DANish Study of Optimal Acute Treatment of Patients with ST-segment Elevation Myocardial Infarction: Ischemic Postconditioning During Primary PCI); EARLY-BAMI (Early- Beta-blocker Administration before primary PCI in patients with ST-elevation Myocardial Infarction); IMMEDIATE (Immediate Myocardial Metabolic Enhancement During Initial Assessment and Treatment in Emergency Care); K-WIND-ANP (Japan-Working groups of acute myocardial infarction for the reduction of Necrotic Damage by ANP); K-WIND-KTP (Japan-Working groups of acute myocardial infarction for the reduction of NecroticDamage by a K-ATP channel opener); METOCARD-CNIC (Effect of METOprolol in CARDioproteCtioN During an Acute Myocardial InfarCtion); MITOCARE (Multicenter, randomized, double-blind, placebo controlled study to assess safety and efficacy of TRO40303 for reduction of reperfusion injury in STEMI patients undergoing primary PCI); MOVE ON! (Impact of Pre-Reperfusion Metoprolol on Clinical Events After Myocardial Infarction); PROMISE (protection with adenosine during primary PCI in patients with STEMI)

Abbreviations: ANP, atrial natriuretic peptide; GIK, Glucose-insulin-potassium; IS, infarct size; IPOST, ischemic postconditioning; IRI, ischemia/reperfusion injury; LVEF, left ventricular ejection fraction; MPTP, mitochondrial permeability transition pore; PPCI, primary percutaneous coronary intervention; RIC, remote ischemic conditioning; ROS, reactive oxygen species; SPECT, single photon emission computed tomography; STEMI, ST-segment elevation myocardial infarction; 


\section{Table 2}

Major differences between pre-clinical animal MI models and the typical patient presenting with an acute MI treated by myocardial reperfusion.

\begin{tabular}{|c|c|c|c|}
\hline Factor & Animal models & STEMI patients & Potential improvements \\
\hline Subject & $\begin{array}{l}\text { Usually young small } \\
\text { animals }\end{array}$ & Middle aged patients & $\begin{array}{l}\text { Use aged large and old } \\
\text { animals }\end{array}$ \\
\hline $\begin{array}{l}\text { Timing of the } \\
\text { intervention }\end{array}$ & $\begin{array}{l}\text { Similar in all animal } \\
\text { models (prior to } \\
\text { ischemia or upon } \\
\text { reperfusion) }\end{array}$ & $\begin{array}{l}\text { It varies between } \\
\text { patients }\end{array}$ & $\begin{array}{l}\text { In clinical studies, } \\
\text { interventions should be } \\
\text { administered according to } \\
\text { those results reported in the } \\
\text { experimental setting }\end{array}$ \\
\hline Infarct size & $\begin{array}{l}\text { Varies from } 30 \% \text { to } \\
60 \% \text { of the total left } \\
\text { ventricular mass }\end{array}$ & $\begin{array}{l}\text { Infarcts are smaller, } \\
\text { limiting the room for } \\
\text { cardioprotection }\end{array}$ & $\begin{array}{l}\text { Clinical study designs } \\
\text { should consider this } \\
\text { difference when calculating } \\
\text { sample size }\end{array}$ \\
\hline MI model & $\begin{array}{l}\text { Most studies use } \\
\text { ligation to occlude a } \\
\text { non-diseased } \\
\text { coronary artery }\end{array}$ & $\begin{array}{l}\text { Atherosclerotic plaque } \\
\text { rupture, other coronary } \\
\text { arteries affected, } \\
\text { inflammatory response }\end{array}$ & $\begin{array}{l}\text { Use animal models of } \\
\text { coronary atherosclerosis. }\end{array}$ \\
\hline Co-morbidities & $\begin{array}{l}\text { Most studies use } \\
\text { non-diseased animals }\end{array}$ & $\begin{array}{l}\text { Multiple co- } \\
\text { morbidities }\end{array}$ & $\begin{array}{l}\text { Use animal models of } \\
\text { diabetes, hyperlipidemia and } \\
\text { aging }\end{array}$ \\
\hline $\begin{array}{l}\text { Concomitant } \\
\text { medication }\end{array}$ & $\begin{array}{l}\text { Single intervention } \\
\text { without concomitant } \\
\text { background drugs }\end{array}$ & $\begin{array}{l}\text { Multiple concomitant } \\
\text { and chronic medication }\end{array}$ & $\begin{array}{l}\text { Use of models conducted on } \\
\text { a background of standard } \\
\text { medication }\end{array}$ \\
\hline $\begin{array}{l}\text { Duration of } \\
\text { myocardial } \\
\text { reperfusion }\end{array}$ & $\begin{array}{l}\text { Fixed and usually } \\
\text { short }\end{array}$ & Continual reperfusion & $\begin{array}{l}\text { Use longer reperfusion } \\
\text { periods }\end{array}$ \\
\hline
\end{tabular}

Abbreviations: STEMI, ST-segment myocardial infarction 


\section{Figure Legends}

Fig. 1. Application of the five accepted criteria to validate IS as a true surrogate endpoint.

Abbreviations: PPCI, primary percutaneous coronary intervention; STEMI, ST-segment elevation myocardial infarction. 